Philipp S. Fischinger

\title{
Haftungsbeschränkung im Bürgerlichen Recht
}

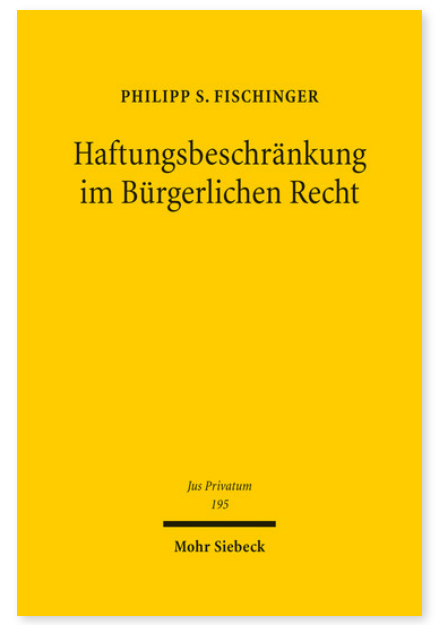

2015. XXXII, 819 Seiten. JusPriv 195

ISBN 978-3-16-153866-7

eBook PDF $179,00 €$

ISBN 978-3-16-153539-0

Leinen $179,00 €$
Ein funktionierendes Haftungssystem ist nicht nur für einen »gerechten« Ausgleich der Interessen von Schuldner und Gläubiger essentiell, sondern ist auch Ausfluss volkswirtschaftlicher und allgemein gesellschaftspolitischer Erfordernisse. Das verlangt einerseits nach Haftungsnormen, die einen effektiven Schutz (potentieller) Geschädigter gewährleisten, andererseits aber auch nach Instrumenten, die diese Haftung sachgemäß begrenzen. Die vorliegende Arbeit sucht - aus dem Blickwinkel der Haftungsbeschränkung - nach der ideal austarierten »goldenen Mitte« zwischen zu viel und zu wenig Haftung. Zu diesem Zweck unterzieht Philipp S. Fischinger verschiedene Haftungsbeschränkungsinstrumente (wie z.B. Haftungshöchstsummen, die Beschränkung der Erben- und der Arbeitnehmerhaftung oder die Restschuldbefreiung) einer kritischen Würdigung und ordnet sie unter Einbeziehung ihrer historischen, ökonomischen, sozialen und kulturellen Hintergründe in den juristischen Gesamtrahmen ein.

Philipp S. Fischinger ist Professor für Bürgerliches Recht, Arbeitsrecht, Handels- und Wirtschaftsrecht sowie Sportrecht an der Universität Mannheim.
Jetzt bestellen:

https://mohrsiebeck.com/buch/haftungsbeschraenkung-im-buergerlichen-recht-9783161538667?no_cache=1 order@mohrsiebeck.com

Telefon: $+49(0) 7071-923-17$

Telefax: +49 (0)7071-51104 